Letter to the Editor

\title{
Dietary sugar added to coffee and tea in pre-menopausal women
}

\author{
Keywords: \\ Coffee \\ Tea \\ Sugar
}

\section{Dear Editor,}

We have read with great interest the paper "Intakes and sources of dietary sugars and their association with metabolic and inflammatory markers." by O'Connor and coworkers [1] and we found their conclusion of importance with a view to clinical prevention. They found that in their large population-based cohort, higher intakes of sugars from non-alcoholic beverages and sugar added to tea, coffee, or cereal were associated with glycaemia and inflammatory markers, while sugars from foods, regardless of whether they were free ornon-free sugars, were not associated.

With reference to the findings reported in the paper, we would like to make the following contribution to the discussion. In a recent analysis performed on 635 healthy pre-menopausal women (age range $45-54$ years) we analysed table sugar added to tea, coffee and beverages that included coffee (i.e. cappuccino). Patients were categorized according to quartile of adherence to Mediterranean Diet. Sugar added to beverages was higher in women in the low quartile of adherence to Mediterranean Diet (low Med Score). This group of women had a lower ABI index, a biomarker of asymptomatic atherosclerosis, compared to women with higher Med Score suggesting that sugar added to beverages could be linked with Mediterranean Diet and atherosclerosis. Coffee and tea were similarly distributed among the quartiles of Med Score [2] however sugar added was higher in women drinking tea as compared with women drinking coffee $(3.6 \pm 1.4$ spoons/day versus $1.7 \pm 1.5$ spoons/day; $\mathrm{p}<0.05)$. Analysis from diet recall had the major limitation of missing data regarding out-of-mealtime drinking.

In addition, we found that the intake of sugar from fruit was higher in women in the highest quartile of Mediterranean Diet. This quartile of Mediterranean lifestyle is characterized by high intake of antioxidants, mainly from fruit and vegetables [3]. In our women population coffee consumption was high, but was mainly related to espresso coffee and to cappuccino.

In Mediterranean countries, coffee and wine are strong antioxidant sources, on contrary tea is relatively less consumed among women population. Due to the effects of caffeine on cardiovascular system it is possible that the intake of caffeine positively influenced the outcome combined with the reduced intake of sugar added to coffee beverages $[3,4]$. Consumption of cola soda and energy drinks was small in these women, because of the mean age of population. Energy drinks as well as caffeinated soda cola beverages are more diffuse in young population [5].

\section{References}

[1] O'Connor L, Imamura F, Brage S, Griffin SJ, Wareham NJ, Forouhi NG. Intakes and sources of dietary sugars and their association with. metabolic and inflammatory markers. Clin Nutr 2018;37:1313-22.

[2] Mattioli AV, Coppi F, Migaldi M, Scicchitano P, Ciccone MM, Farinetti A. Relationship between Mediterranean diet and asymptomatic peripheral arterial disease in a population of pre-menopausal women. Nutr Metabol Cardiovasc Dis 2017 Nov;27(11):985-90. https://doi.org/10.1016/j.numecd.2017.09.011. Epub 2017 Oct 3.

[3] Mattioli AV, Farinetti A, Miloro C, Pedrazzi P, Mattioli G. Influence of coffee and caffeine consumption on atrial fibrillation in hypertensive patients [Epub ahead of print] Nutr Metabol Cardiovasc Dis 2011;21(6):412-7. https://doi.org/ 10.1016/j.numecd.2009.11.003.

[4] Riksen NP, Rongen GA, Smits P. Acute and long-term cardiovascular effects of coffee: implications for coronary heart disease. Pharmacol Therapeut 2009;121. 185-19.

[5] Mattioli AV, Pennella S, Farinetti A, Manenti A. Energy drinks and atrial fibrillation in young adults. Clin Nutr 2018;37:1073-4. https://doi.org/10.1016 j.clnu.2017.05.002. pii: S0261-5614(17)30162-0.

Anna Vittoria Mattioli*, Alberto Farinetti Surgical, Medical and Dental Department of Morphological Sciences related to Transplant, Oncology and Regenerative Medicine, University of Modena and Reggio Emilia Italy

* Corresponding author. E-mail address: annavittoria.mattioli@unimore.it (A.V. Mattioli).

3 January 2018 